\title{
Ectopic Pregnancy at the Thiès (Sénégal) Regional Hospital: A Study of Diagnostic, Therapeutic and Prognostics
}

\author{
Gueye $\mathrm{L}^{1 *}$, Thiam $\mathrm{M}^{2}$, Niang $\mathrm{MM}^{3}$, Ba PA4, \\ Mahammat $\mathrm{S}^{1}$ and Cisse $\mathrm{ML}^{\mathbf{2}}$ \\ ${ }^{1}$ Department of Obstetrics and Gynecology, Thiès \\ Regional Hospital, Thiès, Senegal \\ ${ }^{2}$ University of Thiès, Thiès, Senegal \\ ${ }^{3}$ Department of Obstetrics and Gynecology, University \\ Cheikh Anta Diop of Dakar, Senegal \\ ${ }^{4}$ Department of General Surgery, Thiès Regional Hospital, \\ Thiès, Senegal \\ *Corresponding author: Gueye L, Department of \\ Obstetrics and Gynecology, Thiès Regional Hospital, \\ Thiès, Senegal
}

Received: August 29, 2017; Accepted: September 14, 2017; Published: September 21, 2017

\begin{abstract}
Objective: To evaluate the diagnostic, therapeutic and prognostic aspects of ectopic pregnancy at the Regional Hospital of Thiès.

Methods and Materials: This is a prospective and descriptive study of patients received for Ectopic Pregnancy (EP) and managed in the gynecology and obstetrics department of the regional hospital of Thiès between 1 July 2013 and 31 December 2014. Diagnostic, therapeutic and prognostic aspects were studied. The data was compiled entered and analyzed using the Sphinx version 5 software.
\end{abstract}

Results: We registered 50 EPs from 695 patients presenting with metrorrhagia in the first trimester, which represents a frequency of $7.2 \%$.

The epidemiological profile of the patients was that of a 29 years woman on average, few previous deliveries $(28 \%)$ and referrals $(48 \%)$. For the most part it involved a ruptured EP $(92 \%)$ and of ampulla location (78\%). Forty-nine patients $(98 \%)$ had surgical treatment including 45 salpingectomies (90\%). We had one maternal death, representing a $2 \%$ mortality rate. Fertility after EP was $33 \%$.

Conclusion: EP remains a frequent condition in our hospital. The majority of patients arrive in a state of raptured EP requiring radical surgical interventions

Keywords: Ectopic pregnancy; Laparotomy; Salpingectomy

\section{Introduction}

Ectopic Pregnancy (EP) is the implantation and development of the fertilized egg outside the uterine cavity. It is the leading cause of maternal mortality in the first trimester of pregnancy and is a real public health problem. The prevalence rate remains elevated in developing countries, where diagnosis is often made late after development of complications, thus impacting maternal survival negatively [1]. Through this study, we have wanted to evaluate the diagnostic, therapeutic and prognostic aspects of ectopic pregnancy at the regional hospital of Thiès.

\section{Patients and Methods}

This is a prospective and descriptive study of patients received for Ectopic Pregnancy (EP) and taken care of in the gynecology and obstetrics department of the regional hospital of Thiès between 1 July 2013 and 31 December 2014, a period of 18 months. Diagnostic aspects, management and prognosis were analyzed. Surgical management consisted of emergency laparotomy for ruptured or symptomatic EPs. Medical treatment was reserved for non-raptured and or asymptomatic EPs with a visible gestational sac of less than $4 \mathrm{~cm}$, with a level of $\beta \mathrm{HCG}<5000 \mathrm{IU}$. Methotrexate was administered intramuscularly at a dose of $1 \mathrm{mg} / \mathrm{kg}$ or $50 \mathrm{mg} / \mathrm{m}^{2}$. $\beta$ HCG levels were checked on the $7^{\text {th }}$ day and thereafter once a week until negative. Patient informed consent was necessary. The data were analyzed using the Sphinx version 5 software.

\section{Results}

\section{Epidemiology}

During the study period, we had 50 EPs, representing $7.2 \%$ of first trimester ante partum hemorrhage and $1 \%$ of live births. The epidemiological profile of the patients was that of a woman aged 29 years on average, few previous deliveries (28\%), without any particular medical history (56\%) and referred from another center in $48 \%$ of the cases.

\section{Diagnostic aspects}

The functional signs were dominated by amenorrhea (47 patients, $94 \%$ of cases), pelvic pain (46 patients, $92 \%$ of cases) and metrorrhagia ( $76 \%$ of cases). Forty-two patients $(84 \%)$ presented with peritoneal irritation picture and six patients (12\%) were admitted due hemorrhagic shock. Forty-one patients (82\%) had a pelvic ultrasound and $\mathrm{EP}$ was found in $87.8 \%$ (36 patients). For the other five patients, ultrasound performed outside the hospital diagnosed abortion (2 cases), an ovarian cyst (2 cases), a progressive pregnancy with ascites (1case). Following thorough clinical and / or ultrasound scanning, a positive diagnosis of EP was established in $84 \%$ of cases on admission. These were thirty-eight ruptured EPs (76\%) and 4 non-raptured EPs (8\%). A diagnostic error was noted in $16 \%$ of the cases (Table 1 ).

Culdocentesis was performed in $18 \%$ of the patients, pregnancy tests done in 20 patients (40\%) and a quantitative determination of $\beta \mathrm{HCG}$ in $2 \%$ of cases. One case of heterotopic pregnancy was
Austin J Obstet Gynecol - Volume 4 Issue 2 - 2017

Submit your Manuscript | www.austinpublishinggroup.com

Gueye et al. () All rights are reserved
Citation: Gueye L, Thiam M, Niang MM, Ba PA, Mahammat S and Cisse ML. Ectopic Pregnancy at the Thiès (Sénégal) Regional Hospital: A Study of Diagnostic, Therapeutic and Prognostics. Austin J Obstet Gynecol. 2017; 4(2): 1073 
Table 1: Distribution of patients according to diagnosis on admission.

\begin{tabular}{|c|c|c|}
\hline Admission Diagnosis & Number of Patients & Percentage (\%) \\
\hline Raptured Eps & 38 & 76 \\
\hline Non raptured Eps & 4 & 8 \\
\hline Ovarian Cyst & 2 & 4 \\
\hline Abortion & 2 & 4 \\
\hline Ascites & 4 & 8 \\
\hline Total & 50 & 100 \\
\hline
\end{tabular}

\section{*EPS: Ectopic pregnancies}

Table 2: Distribution of patients according to the localization of the EP $(N=50)$.

\begin{tabular}{|c|c|c|}
\hline Localization & Number of patients & Percentage (\%) \\
\hline Ampullas & 39 & 78 \\
\hline Isthmic & 6 & 12 \\
\hline Infundibular & 4 & 8 \\
\hline Interstitial & 1 & 2 \\
\hline Total & 50 & 100 \\
\hline
\end{tabular}

Table 3: Distribution of patients according to treatment received $(\mathrm{N}=50)$.

\begin{tabular}{|c|c|c|}
\hline Treatment & Number of patients & Percentage (\%) \\
\hline Surgical & 49 & 98 \\
\hline Salpingectomy & 43 & 86 \\
\hline Adnexectomy & 2 & 4 \\
\hline Salpingotomy & 4 & 8 \\
\hline Medical & 1 & 2 \\
\hline
\end{tabular}

recorded. All the ectopic pregnancies were localized in the fallopian tubes, 39 ampullas (76\%), 6 isthmic, and 4 infundibular (Table 2).

\section{Therapeutic aspects}

Forty-nine patients (98\%) were treated surgically. In $90 \%$ of cases, the surgery was radical including salpingectomy or even an adnexectomy (4\%). The approach was by laparotomy in all cases. Medical treatment with methotrexate was used for one patient (2\%) (Table 3).

\section{Prognostic aspects}

The post op follow-up was uncomplicated in 16 of the patients (32\%). Thirty patients (60\%) had anemia and among these, $10(33 \%)$ required blood transfusion. The average hospital stay was 7 days. We had one maternal death, a specific mortality of $2 \%$.

The mortality case was a 23-year-old patient who was admitted to the Department of Medicine for 48 hours for an exploration of ascites before being admitted to our department in a state of hemorrhagic shock resulting in the patient's death on the operating table. Of the fifteen patients followed up for their desire to get pregnant again, 05 (33\%) got pregnant. Two patients had recurrence of EP. We had recorded two abortions and one patient had a normal vaginal delivery.

\section{Discussion}

\section{Frequency}

This high hospital prevalence rate in Senegal was confirmed by Touré [2], who found a frequency of 5.5\% compared to abdominopelvic emergencies in sexually active women. According to Moreau,
EP represented $14 \%$ of abdominal emergency interventions performed at the maternity department of Le Dantec [3]. Although it is difficult to compare these hospital frequency rates, it can be said that the prevalence rate of EP in Senegal remains high in the referral surgical departments. However, when we consider the ratio of live births, our frequency of $1 \%$ was relatively low compared to those found by Kenfack in Cameroon [1] 3.4\% and Diallo FB in Guinea 5.2\% [4]. In Europe and North America, the frequency of EP has tripled over the last thirty years and is estimated at $2 \%$ of live births [5].

The epidemiological profile of our patients has no peculiarities compared to those reported by most authors. Indeed, EP is a pathology of the young sexually active woman, and is associated with low parity [6,7].

\section{Diagnostic aspects}

The classic functional signs were present in our series. These included amenorrhea (95\%), pelvic pain (92\%) and metrorrhagia (76\%). The same was observed by most African authors MAJHI $[2,6]$. We agree with Nayama [7] that in our regions women only consult in the first trimester for signs that may reflect abnormal changes in pregnancy. This may explain the delays in diagnosis and management noted in our patients unlike what is encountered in developed countries [8] where the diagnosis is made early. Six patients (12\%) were in hemorrhagic shock and 30 patients $(60 \%)$ were anemic and of these, $10(33 \%)$ required transfusion. This high rate of patients with hemodynamic instability was also observed in other African series $[6,7,10]$, due to the late diagnosis often at ruptured EP stage. The diagnosis of EP in 42 patients (84\%) was established on admission based on clinical and / or ultrasound evidence. Because quantitative beta-HCG levels were not always available in our resource-constrained countries, we used the urine pregnancy test in 20 patients (40\%). According to the recommendations of the CNGOF, the pregnancy test, which is essential for EP screening, should be performed because it has the advantages of speed and has demonstrated its reliability, sensitivity and specificity [5]. Because of the availability of emergency ultrasound in our structure, the Culdocentesis was only performed in $18 \%$ of cases. However, Culdocentesis still has its value in Africa where it is widely used for the diagnosis of EP $[6,10]$. On the other hand, it may, in some cases, cause digestive or vascular lesions related to the puncture [11].

\section{Therapeutic aspects}

In our series, 49 patients (98\%) had surgery which was radical in 45 patients $(90 \%)$. The same observation was made in most African series $[6,10,12]$. This high rate of radical surgical treatment is explained by the late diagnosis of EP, often at the ruptured STAGE with hemoperitoneum and hemodynamic instability contraindicating medical treatment. Laparotomy was the most commonly used approach in all patients who received surgical treatment. Two explanations could be given for this choice:

1. On one hand, endoscopic equipment is scarcely available in our centers and its use is limited by the inexperience of the operator,

2. On the other hand, the hemodynamic instability secondary to the rupture of the EP constitutes a contraindication to laparoscopy.

However, this method is the "gold standard" in the surgical 
management of the EP and conservative treatment would be in any case preferable. Indeed, according to Bruhat, laparoscopic Salpingotomy is preferred whenever possible for any patient desiring pregnancy because the fertility results are better, even if this conservative treatment exposes one to risks of about $15 \%$ recurrence and trophoblastic persistence [13]. The laparoscopic approach has the advantage of being minimally invasive, which is associated with an earlier discharge and a lower risk of postoperative adhesions compared to laparotomy [9]. We managed one case medically, similar to the Nayama study where only one case of medical treatment was performed [7]. Increased awareness by women of childbearing age associated with equipment in our laboratories would allow more patients with EP to receive medical treatment. Indeed, medical treatment and conservative laparoscopic surgery are the best methods of management of the EP. It is widely proposed in developed countries where diagnosis occurs early [14].

\section{Prognostic aspects}

The complications of EP can be at several levels, namely the immediate complications on the health or even on the life risk of the woman, longer-term complications on the psychological level and on fertility [15]. Thirty patients had anemia requiring transfusion in $32 \%$ of cases. Dohbit et al used transfusion for $2.5 \%$ of their patients and infection in $1.5 \%$ [6]. We recorded a case of death from hemorrhagic shock, i.e. a specific mortality of $2 \%$. Moreau and Baldé respectively described a mortality of $2.6 \%$ and $1.8 \%[3,16]$.

Fertility has become a main public health problem after treatment of EP. Our fertility rate was $33 \%$. This fertility depends on several factors inherent to the patient as well as on the management of the EP itself. The major prognostic factors influencing fertility after EP are the state of the fallopian tubes and age. Medical treatment would tend to improve fertility later. Of the few studies that performed hysterosalpingography, tubal permeability is very reasonable, above $80 \%$. Cumulative rates of pregnancy were about $80 \%$ [17].

\section{Conclusion}

$\mathrm{EP}$ is a frequent and serious pathology of the first trimester of pregnancy whose prognosis is improving in our countries because of the progress noted in the field of resuscitation. The availability of modern diagnostic and therapeutic means and patient awareness for early prenatal consultations could increase the rate of conservative treatment and improve the subsequent fertility of these patients.

\section{References}

1. Kenfack B, Noubom M, Bongoe A, Tsatedem FA, Ngono M. La grossesse extra-utérine dans une région semi-rurale en Afrique: Aspects épidémiologiques, cliniques et thérapeutiques à propos d'une série de 74 cas traités à l'Hôpital de District de Sangmelima au Sud-Cameroun, Pan African Medical Journal. 2012; 13; 71.
2. Toure FB, Diop CT, Thiam O, Toure A, Wade T, Ndiaye D, et al. Prise en charge des grossesses extra-utérines (GEU) au centre hospitalier régional d'Ourossogui (Sénégal). Annales de la SOGGO. 2012; 7: 70 -71.

3. Moreau JC, Ruparil L, Diouf A, Mendes V, Bah M, Diadiou F. Aspects épidémiologiques et anatomocliniques des grossesses extra-utérines au CHU de Dakar. Dakar Médicale. 1995; 40: 175-179.

4. Diallo FB, Diallo AB, Diallo TS, Camara AY, Baldé MA, Diallo $Y$, et al. Grossesse extra- utérine (GEU) : Aspects épidémiologiques et thérapeutiques au service de gynécologie obstétrique du CHU Ignace Deen de Conakry. Médecine d'Afrique Noire. 1999; 46: 42-45.

5. Madelenat P. Prise en charge de la grossesse extra-utérine.-J Gynecol Obstet Biol Reprod. 2003; 32: 6-112.

6. Dohbit JS, Foumane P, Kapche MD. Grossesse extra-utérine à l'Hôpital régional de Bafoussam. Clin Mother Child Health. 2010; 7: 1189-1193.

7. Nayama M, Gallais A, Ousmane N, Idi N, Tahirou A, Garba M, et al. Prise en charge de la grossesse extra-utérine dans les pays en voie de développement: exemple d'une maternité de référence au Niger. Gynécologie Obstétrique \& Fertilité. 2006; 34: 14-18.

8. Majhi AK, Roy N, Karmakar KS, Banerjee Pk. Ectopic pregnancy-an analysis of 180 cases. J Indian Med Assoc. 2007; 105: 308-310.

9. Frey $\mathrm{C}$, Poncelet $\mathrm{C}$. Traitement endoscopique de la grossesse extra-utérine. Gynécologie-Obstétrique et Fertilité. 2011; 39: 640-643.

10. Sindayirwanya JB, Harakeye MG, Ninteretse G, Rufyikiri TH. Aspects particuliers des grossesses extra-utérines au Burundi: à propos de 249 cas. Médecine d'Afrique Noire. 1991; 38: 335-341.

11. Dupuis O, Camagna O, Benifla JL, Batallan A, Dhainaut-Renolleau C et Madelenat P. Grossesse extra-utérine. Encycl med chir, gynécologie/ obstétrique. 2001; 18p.

12. Cissé $\mathrm{M}$, Touré FB, Konaté I, Dieng $\mathrm{M}$, Ka O, Tendeng $\mathrm{J}$, et al. Prise en charge de la grossesse extra uterine rompue dans un service d'urgences digestives. Dakar Med. 2012; 57: 57- 62.

13. Bruhat MA, Manhes H, Mage G, Pouly JL. Treatment of ectopic pregnancies by means of laparoscopy. Fertil Steril. 1980; 33: 411-414.

14. Gervaise A, Fernandez H. Prise en charge diagnostique et thérapeutique des grossesses extra-utérine. J Gynecol Obstet Biol Reprod. 2010; 39: 17-24.

15. Bouyer J. Epidémiologie de la grossesse extra-utérine: incidence, facteurs de risque et conséquences. J Gynecol Obstet Biol Reprod. 2003; 32: 8-17.

16. Balde IS, Diallo FB, Diallo MH, Sylla I. Prise en charge de la grossesse extra utérine à Conakry. Médecine et Santé Tropicales. 2014; 24: 297-300.

17. Tuomivaara L, Kauppila A. Radical or conservative surgery for ectopic pregnancy?A follow-up of fertility of 323 patients. Fertil Steril. 1988; 50: 580583.
Austin J Obstet Gynecol - Volume 4 Issue 2 - 2017

Submit your Manuscript | www.austinpublishing group.com

Gueye et al. (C) All rights are reserved
Citation: Gueye L, Thiam M, Niang MM, Ba PA, Mahammat S and Cisse ML. Ectopic Pregnancy at the Thiès (Sénégal) Regional Hospital: A Study of Diagnostic, Therapeutic and Prognostics. Austin J Obstet Gynecol. 2017; 4(2): 1073 